Article

\title{
Study on the Improvement of Electrical Facility System of Automated External Defibrillators by Real-Time Measurement of Thoracic Impedance
}

\author{
Tae-Jin Ha ${ }^{1}$, Hong-Gyu Park ${ }^{2}$, Su-Kang Park ${ }^{3}$ and Sang-Geon Park ${ }^{4, *}$ \\ 1 Department of Electrical and Electronic Engineering, Silla University, 140 Baegyang-daero 700beon-gil, \\ Sasang-gu, Busan 46958, Korea; bnb820711@naver.com \\ 2 Department of Electrical, Electronic Control Engineering, Changwon National University, \\ 20 Changwondaehak-ro, Uichang-gu, Changwon-si 51140, Gyeongsangnam-do, Korea; \\ hgpark@changwon.ac.kr \\ 3 Department of Korea Testing Certification, 22 Heungan-daero 27 beon-gil, Gunpo, \\ Gyeonggi-do 15809, Korea; park2355@ktc.re.kr \\ 4 Department of Mechatronics Convergence, Changwon National University, 20 Changwondaehak-ro, \\ Uichang-gu, Changwon-si, Gyeongsangnam-do 51140, Korea \\ * Correspondence: sgpark@changwon.ac.kr; Tel.: +82-10-5954-8030
}

Received: 20 March 2020; Accepted: 8 May 2020; Published: 10 May 2020

\begin{abstract}
Sudden Cardiac Arrest (SCA) is a serious emergency disease that has increased steadily every year. To this end, an Automated External Defibrillator (AED) is placed in a public place so that even non-professional medical personnel can respond to SCA. However, the thoracic impedance of patients changes due to CardioPulmonary Resuscitation (CPR) and artificial respiration during first aid treatment. In addition, changes in chest statues due to gender, age, and accidents cause changes in thoracic impedance in real time. The change in thoracic impedance caused by this has a negative effect on the intended electrical energy of the automatic heart shocker to the emergency patient. To prove this, we divided it into adult and pediatric modes and experimented with the energy error of the AED according to the same impedance change. When the first peak current was up to 56.4 (A) and at least 8.4 (A) in the adult mode, the first peak current was up to 32.2 (A) and at least 4.8 (A), respectively, when the impedance changed, the error of the current figure occurred. In this paper, the inverse relationship between thoracic impedance and electric shock energy according to the state of the cardiac arrest patient is demonstrated through the results of the experiment, and the need for an electric facility system that can revise for changes in thoracic impedance of the cardiac arrest patient by reflecting them on electric shock energy in real time is presented.
\end{abstract}

Keywords: Automated External Defibrillators (AEDs); thoracic impedance; Sudden Cardiac Arrest (SCA)

\section{Introduction}

Cardiopulmonary arrest is a phenomenon in which the heart fails to contract efficiently and the general circulatory system of blood stops. The cardiac arrest is mostly caused by a heart attack that causes blood flow to the heart muscle. The Golden Time of cardiac arrest is $4 \mathrm{~min}$, and after $4 \mathrm{~min}$ the survival rate is dramatically lowered. According to the recent "Joint Survey on Sudden Cardiac Arrest" by the National Fire Agency and Korea Centers for Disease Control \& Prevention, the number of domestic cardiac arrest patients increased from 21,905 in 2008 to 29,262 in 2017, which corresponds to an increase of $33.6 \%$ (7357 patients) over 10 years [1-3]. To address this, the government has mandated the installation of Automated External Defibrillators (AEDs) in public health clinics, firefighting emergency medical services, ambulances, airports, vessels weighing $>20$ tons, public facilities, and apartments 
of more than 500 households under the Emergency Medical Service Act, since 2012. Additionally, measures for the treatment of Sudden Cardiac Arrest (SCA) are available nationwide. As a result, the survival rate of patients with SCA increased from $2.3 \%$ in 2006 to $8.7 \%$ in 2017, a 4-fold increase, but SCA remains an emergency disease with a low survival rate [4-7].

Most of the AEDs currently installed and used by various institutions use 2 pads to separate the output for adults and children while delivering electric shocks. An Electrocardiogram (ECG) analysis is performed using 2 pads to identify the required degree of shock to the heart. However, during basic life support procedures such as artificial respiration and CardioPulmonary Resuscitation (CPR), thoracic impedance may change due to changes in blood flow, thoracic cavity pressure, and shape. $\mathrm{CPR}$ is a first aid that supplies blood containing oxygen to the heart and brain on behalf of a stationary heart. CPR is an essential first aid for patients with cardiac arrest, but on the contrary, when chest compression is performed, it causes changes in thoracic impedance along with internal organ damage such as fractures, liver and spleen damage. This change may hinder the proper transmission of electric shock energy by the AED. This is due to a limitation in the amount of energy transferred according to thoracic impedance. The modes are classified into adult and pediatric modes [8].

Until now, the impedance measurement function of the AED has been used to select adult and pediatric age groups. In connection with this, researches on real-time thoracic impedance measurement method, performance evaluation method, and the effect of CPR on bio-impedance have been conducted. Based on these previous researches, this paper compares the difference in the amount of energy transferred according to the change of thoracic impedance when using an AED installed in public facilities, and the inverse relationship between thoracic impedance and electric energy is verified. Additionally, we aimed to analyze the improvement method to accurately transfer energy to the patient through real-time measurement of thoracic impedance along with electrocardiogram analysis through pads.

\section{Materials and Methods}

\subsection{Principles of $A E D$}

An AED is a device that restores normal rhythm by sending an electric shock directly to the heart or by attaching 2 pads, one under the right clavicle and the other under the axilla next to the left papilla for a cardiac arrest, ventricular fibrillation, or ventricular tachycardia [9]. After attaching the pads, the AED analyzes the ECG and determines whether defibrillation is necessary. Then, the impedance of the first patient is analyzed to determine adult and pediatric ages. If required, it selects the adult or pediatric mode, and defibrillation is performed by pressing a button, followed by CPR. A conventional electric shock is monophasic and current is delivered once in a certain direction. However, this method can cause side effects such as muscle loss because a large amount of energy is applied to the periphery of the pad or the patient's body. Recently, the biphasic method, which uses 2 pads and delivers 2 electric shocks (less than the energy transmitted by a conventional method) is used which improves the efficiency of the electric shock and minimizes side effects such as muscle loss [10,11].

An AED is designed for easy use during an emergency by the general public who lack medical knowledge. It can also be used to analyze the ECG for other purposes such as for the investigation of ventricular fibrillation and arrhythmia.

\subsection{Measurement Principles of Thoracic Impedance}

The thoracic impedance measures changes in bio-impedance that occurs when the heart contracts or relaxes, or during respiration. The thorax is composed of different tissues and resistance between them changes most sensitively in response to air, in addition to breathing. This causes the greatest change in bio-impedance with the largest change in lung capacity [12]. It is possible to measure the change in thoracic impedance in real-time by delivering a specific frequency and measuring the difference in the signal due to the change in impedance $[13,14]$. Based on these principles, it is also 
possible to identify the electrical signals due to changes in the volume of air in the thorax, blood flow, and sternal changes during breathing by using the conventional AED pads [15]. In other words, changes in thoracic impedance can be observed in real time [16,17].

This thoracic impedance real-time measurement technique can help correct the energy of the AED and provide information on the patient's body fat and lung disease. This information can enable prompt examination and treatment during transfer of a patient to a hospital $[18,19]$.

\subsection{Changes in Impedance According to $C P R$}

When a patient undergoes a cardiac arrest, basic life support, including CPR, is given. During this time, the size of the thoracic impedance is determined by factors such as shape, sternum, and muscles of the thoracic region [20]. A sternal fracture often occurs during a patient's fall or during CPR, and if the shape of the sternum changes due to such fractures, impedance may be reduced. In addition, impedance is affected by the pressure applied to the chest during CPR and changes in the blood flow [21-23].

We refer to a studies that measures the change of mechanical impedance of patients during CPR [24-26]. In order to investigate the relationship between CPR strength and periodic changes in bioelectrical impedance, CPR experiments were conducted on the experimental body made by applying different modulus of elasticity of springs in the human body model. Figure 1 shows 2 graphs with different elastic factors and the change in impedance according to frequency. In Figure 1, the horizontal axis of the graph represents the cycle of CPR, and the vertical axis indicates the mechanical impedance change of the human body model. Using the different elasticity modulus of the CPR equipment, the impedance was $80 \Omega$ when the frequency was $2 \mathrm{~Hz}$ in a case of $680 \mathrm{kgf} / \mathrm{m}$ and the impedance was $100 \Omega$ when the frequency was $2 \mathrm{~Hz}$ in a case of $942 \mathrm{kgf} / \mathrm{m}$. At the same frequency, there was a difference of about $20 \Omega$, depending on the elastic modulus. On comparing the impedance values of the 2 cases, it can be seen that a larger elastic modulus is related to larger impedance, and the lower the frequency, the larger the impedance.

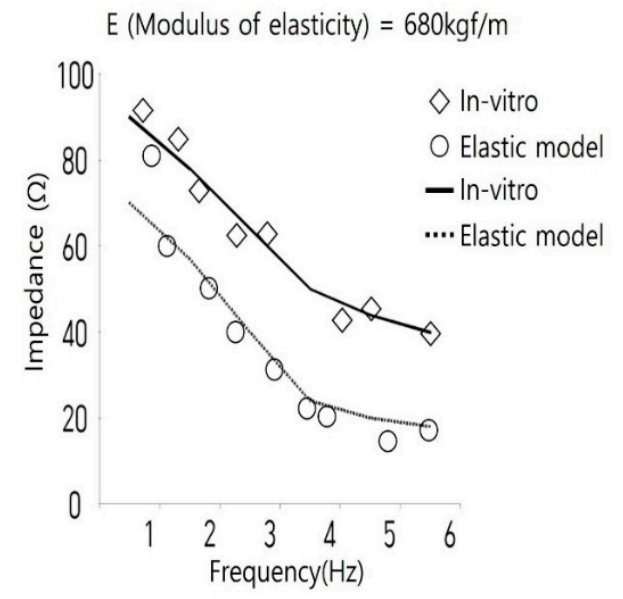

(a)

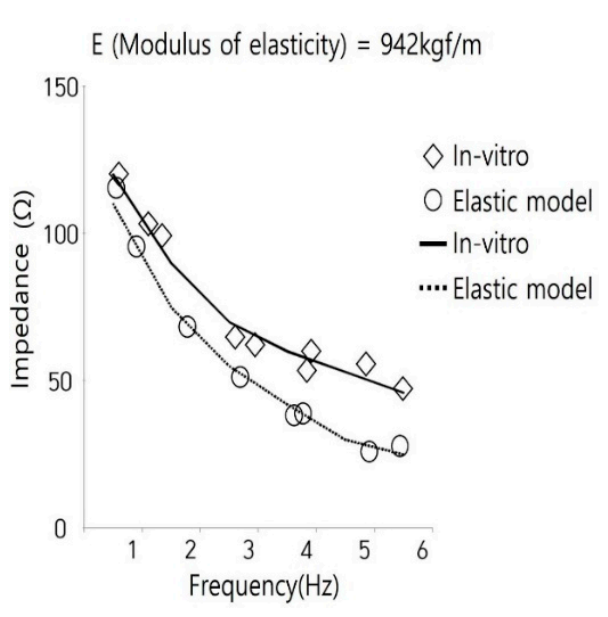

(b)

Figure 1. Impedance by elastic factor: (a) Modulus of elasticity at 680, (b) Modulus of elasticity at 942.

Here, frequency indicates the number of CPR compressions, and the change in impedance is sensitive to the CPR cycles and intensity. This can indicate whether the CPR was performed accurately. Based on these changes, we can observe changes in the sternum and thus detect changes in the thoracic impedance [27]. 


\subsection{Experimental Methods}

Based on the principles for measuring thoracic impedance (Section 2.2) and the changes in impedance that occur during basic life support treatment such as CPR (Section 2.3), the changes in electric shock energy transfer caused by changes in thoracic impedance were examined.

The changes in the performance of 6 items during the electric shock energy experiment were analyzed, including: output energy, emitted energy, biphasic discharge time at $50 \Omega$, accuracy of energy in the pediatric mode, accuracy of energy transfer according to thoracic impedance, and impedance measurement range.

The AED test jig used in the experiment is a device for testing the electrical shock energy of AED. The AED test jig can adjust the mechanical resistance applied to the electrode pad of the AED and can verify the performance of the AED. The electrical phenomenon which generates when the AED test jig being connected to the oscilloscope and applying the electric shock in AED can be observed.

As an experimental method of electric shock energy, the AED was connected to the AED test jig and the ECG output waveform of the AED test jig was set to Ventricular fibrillation (VF). After selecting the adult mode, the electric shock was delivered to the AED test jig, and the discharge time and amount of discharged energy were measured. In order to verify whether the thoracic impedance of the patient changed, the impedance was sequentially changed to $25,50,75,100,125,150$, and $175 \Omega$. After changing the AED to the pediatric mode, the electric shock was delivered to the AED test jig, and output data were again measured and the impedance was changed with the same values as in the adult mode.

The experiment was based on the discharge of electric shock energy of $150 \mathrm{~J}$ for adults and $50 \mathrm{~J}$ for children. Figure 2 shows the actual experiment being carried out. The electric shock energy test was conducted by applying IEC60601-2-4: 2010 (Medical electrical equipment-part 2-4 Particular requirements for the basic safety and essential performance of cardiac defibrillators.) in Table 1. IEC is the international electrotechnical commission, an international standard for facilitating cooperation among countries on issues and related matters concerning standardization in the electrical and electronics sector. IEC60601 is the standard for electrical and electronic medical devices, and IEC60601-2-4:2010 is the international standard for special requirements for basic safety and essential performance of cardiac defibrillators.

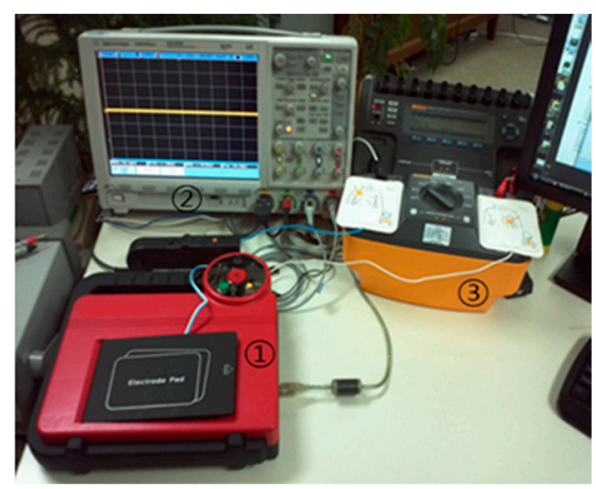

Figure 2. Experimental equipment and setting. (1) Automated External Defibrillator (AED) (2) Oscilloscope (3) AED JIG).

Table 1. Electric shock energy test application standard.

\begin{tabular}{cr}
\hline Name & Description \\
\hline IEC 60601-2-4:2010 & $\begin{array}{c}\text { Medical electrical equipment-part 2-4: Particular requirements for the } \\
\text { basic safety and essential performance of cardiac defibrillators. }\end{array}$ \\
\hline
\end{tabular}




\section{Results}

The jig was connected to the AED, and changes in the electric shock energy per impedance were experimentally tested in the adult pediatric modes. On applying 150 J energy in the adult mode, the maximum energy was $156 \mathrm{~J}$ and the minimum was $148.4 \mathrm{~J}$, which was greater by $4 \%$ and smaller by $1.07 \%$, respectively. When $50 \mathrm{~J}$ was applied in the pediatric mode, the maximum energy was $50.4 \mathrm{~J}$ and the minimum was $49.0 \mathrm{~J}$, which was $0.8 \%$ greater and $2 \%$ smaller, respectively.

Figures 3 and 4 indicate changes in the current discharge time of AEDs in adult and pediatric modes, respectively. (a) is $25 \Omega$, (b) is $175 \Omega$, and the current discharge time is the result of experimenting. The horizontal axis of each graph represents the discharge time when using AED, and the vertical axis represents the peak current value generated during the electric shock of AED.

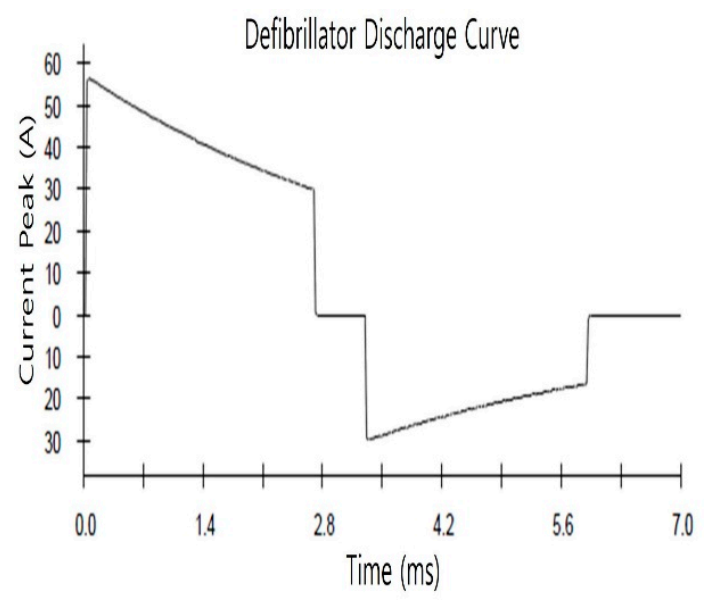

(a)

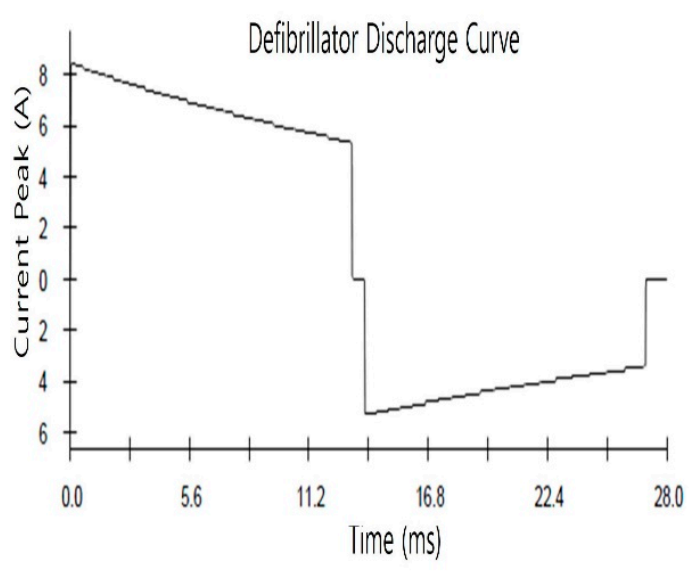

(b)

Figure 3. Adult mode of peak current: (a) $25 \Omega$ Adult mode of peak current, (b) $175 \Omega$ Adult mode of peak current.

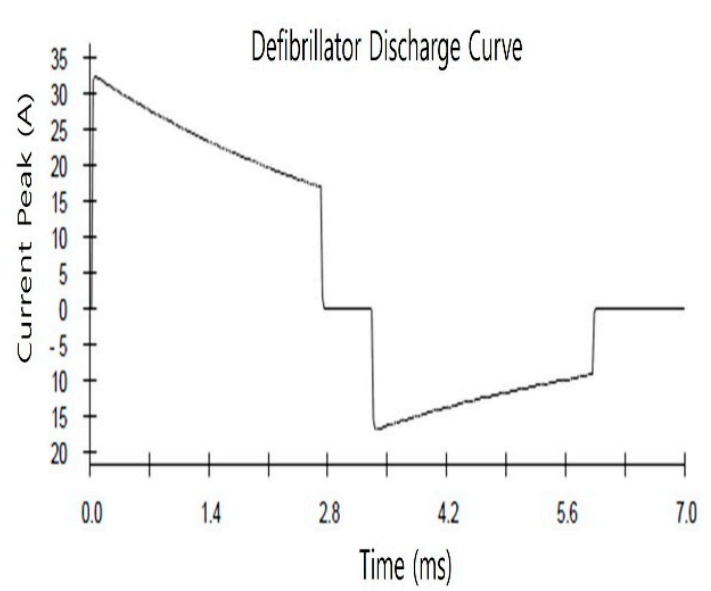

(a)

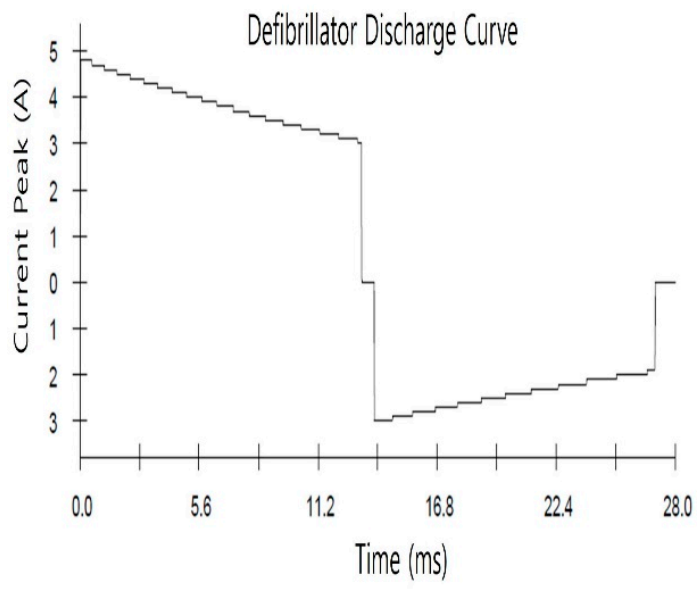

(b)

Figure 4. Pediatric mode of peak current: (a) $25 \Omega$ Pediatric mode of peak current, (b) $175 \Omega$ Pediatric mode of peak current.

Figures 3 and 4 show that the discharge time was $2.7 \mathrm{~ms}$ when the impedance was $25 \Omega$ and the discharge time was 13.2 ms when the impedance was $175 \Omega$ in the adult and pediatric modes, respectively. This indicates that there is a difference in discharge time when an electric shock is applied in proportion to the impedance. An increase in discharge time indicates an increase in the time it takes to transfer the electric energy. This shows that there is an inverse relationship between thoracic 
impedance and electric shock, which has a negative impact on the electric shock energy transferred. This suggests that in SCA patients in which an urgency in the unit of second is required, impedance may negatively affect resuscitation of the patient. Comparing the performances are shown in Table 2, Table 3.

Table 2. Test result table for electric shock energy in adult mode.

\begin{tabular}{cccccc}
\hline $\begin{array}{c}\text { Impedance } \\
(\boldsymbol{\Omega})\end{array}$ & $\begin{array}{c}\text { First Peak } \\
\text { Voltage } \\
(\mathbf{v})\end{array}$ & $\begin{array}{c}\text { First Peak } \\
\text { Current } \\
(\mathbf{A})\end{array}$ & $\begin{array}{c}\text { Second Peak } \\
\text { Voltage } \\
(\mathbf{V})\end{array}$ & $\begin{array}{c}\text { Second Peak } \\
\text { Current } \\
(\mathbf{A})\end{array}$ & $\begin{array}{c}\text { Amount of } \\
\text { Energy } \\
\mathbf{( J )}\end{array}$ \\
\hline 25 & 1411 & 56.4 & 1044 & 29.8 & 156.0 \\
50 & 1423 & 28.5 & 848 & 17.0 & 148.4 \\
75 & 1467 & 19.6 & 906 & 12.1 & 153.5 \\
100 & 1462 & 14.6 & 914 & 9.1 & 150.8 \\
125 & 1468 & 11.7 & 925 & 7.4 & 151.3 \\
150 & 1471 & 9.8 & 930 & 6.2 & 150.7 \\
175 & 1474 & 8.4 & 935 & 5.3 & 150.9 \\
\hline
\end{tabular}

Table 3. Test result table for electric shock energy in pediatric mode.

\begin{tabular}{cccccc}
\hline $\begin{array}{c}\text { Impedance } \\
(\boldsymbol{\Omega})\end{array}$ & $\begin{array}{c}\text { First Peak } \\
\text { Voltage } \\
(\mathbf{v})\end{array}$ & $\begin{array}{c}\text { First Peak } \\
\text { Current } \\
(\mathbf{A})\end{array}$ & $\begin{array}{c}\text { Second Peak } \\
\text { Voltage } \\
(\mathbf{V})\end{array}$ & $\begin{array}{c}\text { Second Peak } \\
\text { Current } \\
(\mathbf{A})\end{array}$ & $\begin{array}{c}\text { Amount of } \\
\text { Energy } \\
(\mathbf{J})\end{array}$ \\
\hline 25 & 807 & 32.2 & 420 & 16.8 & 50.4 \\
50 & 829 & 16.5 & 489 & 9.8 & 49.6 \\
75 & 840 & 11.2 & 513 & 6.8 & 49.4 \\
100 & 844 & 8.4 & 522 & 5.2 & 49.6 \\
125 & 843 & 6.7 & 525 & 4.2 & 49.0 \\
150 & 846 & 5.6 & 528 & 3.5 & 49.2 \\
175 & 847 & 4.8 & 532 & 3.0 & 49.0 \\
\hline
\end{tabular}

In the adult mode, when the 1st peak current was 56.6 (A) 8.4 (A), the impedance was $25 \Omega$ and $175 \Omega$, respectively. As the impedance increased by $25 \Omega$, the 1 st peak current decreased to $27.9(\mathrm{~A})$, 8.9 (A), 5 (A), $2.9(\mathrm{~A}), 1.9(\mathrm{~A})$, and $1.4(\mathrm{~A})$, respectively.

In addition, the second peak current was $29.8(\mathrm{~A}), 17.0(\mathrm{~A})$, and $5.3(\mathrm{~A})$, the impedance was $25 \Omega$ and $175 \Omega$, respectively. As impedance increased by $25 \Omega$, the second peak current decreased by $12.8(\mathrm{~A}), 4.9(\mathrm{~A}), 3(\mathrm{~A}), 1.7(\mathrm{~A}), 1.2(\mathrm{~A})$, and $0.9(\mathrm{~A})$, respectively.

In the pediatric mode, the 1st peak current was 32.2 (A) 4.8 (A), the impedance was $25 \Omega$ and $175 \Omega$, respectively. As impedance increased by $25 \Omega$, the 1st peak current decreased by $15.7(\mathrm{~A})$, $5.3(\mathrm{~A}), 2.8(\mathrm{~A}), 1.7(\mathrm{~A}), 1.1(\mathrm{~A})$, and $0.8(\mathrm{~A})$, respectively.

When the 2nd peak current was 16.8 (A) 3.0 (A), the impedance was $25 \Omega 175 \Omega$, respectively. As impedance increased by $25 \Omega$, the 2nd peak current decreased by 7 (A), 3 (A), $1.6(\mathrm{~A}), 1$ (A), 0.7 (A), and $0.5(\mathrm{~A})$, respectively.

\section{Discussion}

Figure 5 graph shows the relationship between impedance and 1st peak current in the adult and pediatric modes. The experimental results show an inverse relationship between current and impedance in the adult mode and pediatric mode. In other words, the higher the impedance, the lower the output current. The low current indicates that although the total energy may not change much, the current density is lowered due to the increase in impedance during the energy transfer process. This means that when an electric shock is delivered to the patient, the amount of energy transferred is inaccurate. 


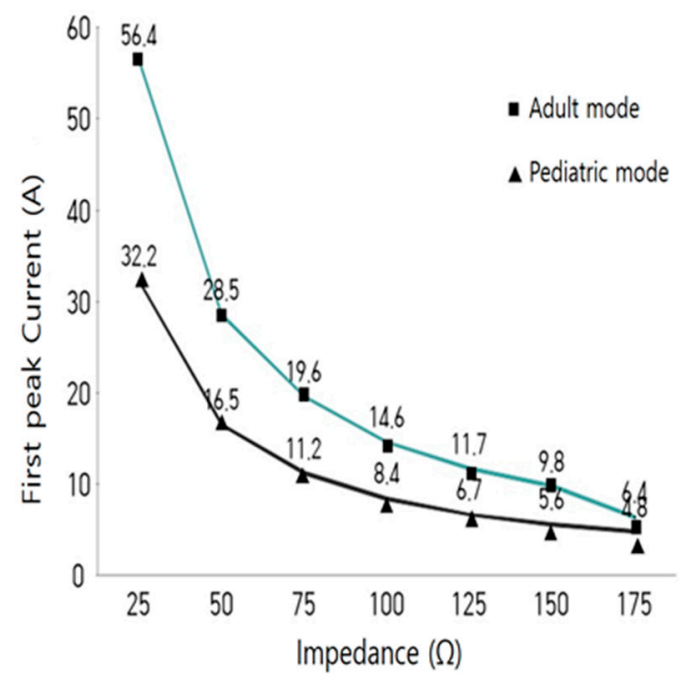

Figure 5. Relationship between impedance and peak current in adult mode and pediatric mode, respectively.

\section{Conclusions}

This study the need to improve the energy accuracy of AED used in emergency patients such as SCA. The results of the study showed that changes in thoracic impedance due to various factors such as patient status and first aid process had a negative effect on the energy delivery of the AED. The experiment was conducted based on the international standard IEC60601-2-4:2010 of medical devices. The electric shock energy error was measured by changing the impedance of each adult mode and pediatric mode of the AED. When the impedance is changed and set to adult mode, the first peak current of the shock energy is set to 55.4 (A), at least 8.4 (A), and the first peak current is set to 32.2 (A) and at least $4.8(\mathrm{~A})$ when the pediatric mode is set. Experimental results show that the change in the thoracic impedance of the patient is inversely proportional to the decrease in the peak current of the electric energy applied by the AED.

The AED analyzes ECG and thoracic impedance of early emergency patients through pads to provide information on whether defibrillation is necessary and decisions of adult or pediatric mode. However, thoracic impedance can change in the process of first aid treatment to patients. The changing thoracic impedance can be improved by various measure such as correcting the electric shock energy by analyzing the change of impedance by continuously applying a specific Alternating Current (AC) signal to the human body through the pad. This can increase the survival rate of patients with cardiac arrest by delivering accurate electric energy required for the patient.

In the Guidance for Medical Device Performance Test published by the Korea Food and Drug administration in 2010, the test criteria for the accuracy of output energy among the performance evaluation items of AEDs are $\pm 3 \mathrm{~J}$ or $\pm 15 \%$ [28]. However, most of the AEDs installed in public places are used by non-professional medical personnel. Therefore, the test performance standards for AEDs should be stricter. Especially in the case of children, the elderly, and pregnant women, the performance deterioration due to the energy error for the thoracic impedance change can have a big designation for life. Therefore, the pad of the AED is required to analyze the changes in the thoracic impedance of the patient in real time and to revise the electric shock energy. In the case of ventricular fibrillation emergency patients, the probability of defibrillation success is reduced by about $10 \%$ every minute, so quick and accurate response to cardiac arrest is the most important part of protecting life. Since the AED used in this way is a medical device developed for all the public to use, continuous research should be conducted to demonstrate accurate performance to emergency patients even when non-specialized medical personnel use it according to its purpose and goal performance. 
Author Contributions: Conceptualization, T.-J.H.; methodology, H.-G.P.; validation, H.-G.P.; formal analysis, T.-J.H.; investigation, T.-J.H.; resources, S.-K.P.; data curation, T.-J.H.; writing-original draft preparation, T.-J.H.; writing-review and editing, S.-G.P.; visualization, T.-J.H.; supervision, S.-G.P.; project administration, S.-G.P.; funding acquisition, H.-G.P. All authors have read and agreed to the published version of the manuscript.

Funding: This research was supported by Changwon National University in 2020 2021.

Conflicts of Interest: The authors declare no conflict of interest.

\section{References}

1. Kim, Y.T. Sudden Cardiac Arrest Survey 2006-2016; Korean Center for Disease Control: Chungcheongbuk-do, Korea, 2017.

2. Park, S.J.; Park, S.M.; Kang, S.M.; Choi, S.W. Real-time monitoring of blood flow using mechanical impedance of chest during CPR. Korean Soc. Mech. Eng. 2017, 11, 2377-2379.

3. Lwami, T.; Kitamura, T.; Kawamura, T.; Mitamura, H.; Nagao, K.; Takayama, M.; Seino, Y.; Tanaka, H.; Nonogi, H.; Yonemoto, N.; et al. Chest compression-only cardiopulmonary resuscitation for out-of-hospital cardiac arrest with public-access defibrillation. Circulation 2012, 126, 2844-2851.

4. Adabă̆, S.A.; Hodgson, L.; Garcia, S.A.; Anand, V.; Frascone, R.J.; Conterato, M.; Lick, C.J.; Wesley, K.; Mahoney, B.D.; Yannopoulos, D. Outcomes of sudden cardiac arrest in a state-wide integrated resuscitation program: Results from the minnesota resuscitation consortium. Resuscitation 2017, 110, 95-100. [CrossRef]

5. Fernando, S.; Vaillancourt, C.; Morrow, S.; Stiell, I.G. Analysis of bystander CPR quality during out-of-hospital cardiac arrest using data derived from automated external defibrillators. Resuscitation 2018, 128, 138-143. [CrossRef]

6. Morrow, W.; Berger, S.; Jenkins, K.; Minich, L.; Rosenthal, G.L.; Snyder, C.S.; Twedell, J.; Beekman, R.H.; Klitzner, T.S.; Manning, P.B.; et al. Pediatric sudden cardiac arrest. Pediatrics 2012, 129, 1094-1102.

7. Marijon, E.; Uy-Evanado, A.; Dumas, F.; Karam, N.; Reinier, K.; Teodorescu, C.; Narayanan, K.; Gunson, K.; Jui, J.; Jouven, X.; et al. Warning symptoms are associated with survival from sudden cardiac arrest. Ann. Intern. Med. 2016, 164, 9-23. [CrossRef]

8. Mercier, E.; Laroche, E.; Beck, B.; Sage, N.L.; Cameron, P.A.; Émond, M.; Berthelot, S.; Mitra, B.; Ouellet-Pelletier, J. Defibrillation energy dose during pediatric cardiac arrest: Systematic review of human and animal model studies. Resuscitation 2019, 139, 241-252. [CrossRef]

9. Cho, H.R.; Jo, H.S.; Kim, D.M.; Ha, T.J.; Baek, M.G.; Park, S.K.; Park, S.G. Study on safety requirements and test methods for automated external defibrillators. Infor. Control Symp. 2018, 18, 213-214.

10. Ristagno, G.; Yu, T.; Quan, W.; Freeman, G.A.; Locke, E. Comparison of defibrillation efficacy between two pads placements in a pediatric porcine model of cardiac arrest. Resuscitation 2012, 83, 755-759. [CrossRef]

11. Piuzzi, E.; Pisa, S.; Pittella, E.; Podestà, L.; Sangiovanni, S. Comparison among low-cost portable systems for thoracic impedance plethysmography. In Proceedings of the 2017 IEEE International Instrumentation and Measurement Technology Conference, Torino, Italy, 22-25 May 2017; pp. 1-6.

12. Cho, Y.C.; Kim, M.S.; Yoon, J.O. A study on the electrical difference for the limbs and thoracic impedance using real-time bio-impedance measurement system. J. Korea Ind. Inf. Syst. Res. 2013, 18, 9-16.

13. Park, J.Y. Enhancement of Automatic Defibrillator Simulated Algorithm by ECG and Chest Impedance Signal Analysis. Master's Thesis, Yonsei University, Seoul, Korea, 2015.

14. Alonso, E.; Aramendi, E.; Daya, M.; Irusta, U.; Chicote, B.; Russell, J.; Tereshchenko, L. Circulation detection using the electrocardiogram and the thoracic impedance acquired by defibrillation pads. Resuscitation 2016, 99, 56-62. [CrossRef] [PubMed]

15. Losert, H.; Risdal, M.; Sterz, F.; Nysæther, J.B.; Köhler, K.W.; Eftestøl, T.C.; Wandaller, C.; Myklebust, H.; Uray, T.; Aase, S.O.; et al. Thoracic-impedance changes measured via defibrillator pads can monitor signs of circulation. Resuscitation 2007, 73, 221-228. [CrossRef] [PubMed]

16. Zhao, H.; Kuang, S.J.; He, B.Q.; Wang, Z.M.; Cheng, X.L. Measurement method and principle for thoracic impedance graph. MATEC Web Conf. 2017, 128, 4.

17. Kabiri, L.S.; Hernandez, D.; Mitchell, K. Reliability, validity, and diagnostic value of a pediatric bioelectrical impedance analysis scale. Child. Obes. 2015, 11, 650-655. [CrossRef]

18. González-Otero, D.M.; Gauna, S.R.D.; Ruiz, J.J.; Ayala, U.; Alonso, E. Automatic detection of chest compression pauses using the transthoracic impedance signal. Comput. Cardiol. 2012, 39, 21-24. 
19. Ruiz, J.M.; Alonso, E.; Aramendi, E.; Kramer-Johansen, J.; Eftestøl, T.C.; Ayala, U.; Gonzalez-Otero, D. Reliable extraction of the circulation component in the thoracic impedance measured by defibrillation pads. Resuscitation 2013, 84, 1345-1352. [CrossRef]

20. Meredith-Jones, K.; Williams, S.; Taylor, R. Bioelectrical impedance as a measure of change in body composition in young children. Pediatr. Obes. 2015, 10, 252-259. [CrossRef]

21. Ruiz, J.M.; Gauna, S.R.D.; Gonzalez-Otero, D.; Saiz, P.; Gutiérrez, J.J.; Veintemillas, J.F.; Bastida, J.M.; Alonso, D. Circulation assessment by automated external defibrillators during cardiopulmonary resuscitation. Resuscitation 2018, 128, 158-163. [CrossRef]

22. Kwok, H.; Coult, J.; Liu, C.; Blackwood, J.; Kudenchuk, P.J.; Rea, T.D.; Sherman, L.D. An accurate method for real-time chest compression detection from the impedance signal. Resuscitation 2016, 105, 22-28. [CrossRef]

23. Gruber, J.; Stumpf, D.; Zapletal, B.; Neuhold, S.; Fischer, H. Real-time feedback systems in CPR. Trends Anaesth. Crit. Care 2012, 2, 287-297. [CrossRef]

24. Lee, D.Y.; Kang, S.M.; Choi, S.W. Mechanical impedance monitoring system of the patient's chest during cardiopulmonary resuscitation. Korean Soc. Mech. Eng. 2018, 42, 583-587. [CrossRef]

25. Berve, P.O.; Irusta, U.; Kramer-Johansen, J.; Skålhegg, T.; Kongsgård, H.W.; Brunborg, C.; Aramendi, E.; Wik, L. Transthoracic impedance measured with defibrillator pads-New interpretations of signal change induced by ventilations. Clin. Med. 2019, 8, 724. [CrossRef] [PubMed]

26. Kang, S.M.; Choi, S.W. Monitoring mechanical impedance of the thorax with compression and decompression cardiopulmonary resuscitation device. J. Mech. Sci. Technol. 2019, 33, 981-988. [CrossRef]

27. Arbogast, K.B.; Maltese, M.; Nadkarni, V.; Steen, P.A.; Nysæther, J. Anterior-posterior thoracic force-deflection characteristics measured during cardiopulmonary resuscitation: Comparison to post-mortem human subject data. Stapp Car Crash J. 2006, 50, 131-145. [PubMed]

28. Medical Device Performance Test Guidance 2010; Korean Food and Drug Administration: Seoul, Korea, 2010.

(C) 2020 by the authors. Licensee MDPI, Basel, Switzerland. This article is an open access article distributed under the terms and conditions of the Creative Commons Attribution (CC BY) license (http://creativecommons.org/licenses/by/4.0/). 